\title{
MEASUREMENT OF AIR SPRINGS VOLUME USING INDIRECT METHOD IN THE DESIGN OF SELECTED PNEUMATIC DEVICES
}

\author{
Matej URBANSKÝ*, Jaroslav HOMIŠIN*, Peter KAŠŠAY*, Jozef KRAJŇÁK* \\ *Faculty of Mechanical Engineering, Technical University of Košice, Letná 9, 040 01, Košice, Slovakia \\ matej.urbansky@tuke.sk, jaroslav.homisin@tuke.sk, peter.kassay@tuke.sk, jozef.krajnak@tuke.sk
}

received 14 April 2016, revised 27 February 2018, accepted 2 March 2018

\begin{abstract}
At our department, we deal with continuous tuning of torsional oscillating mechanical systems (TOMS) during their operation in terms of torsional oscillation size. Therefore, a new mobile mechanical system was built for purposes of research and presentation of the TOMS continuous tuning using extremal control method, which main advantage is that we do not need to know a mathematical model of the mechanical system. The new mobile device is equipped with a special compressed air distribution system, which important components are air springs. The air springs are modified and used as air pressure tanks with various functions in the mobile device. Therefore, it is important to know the magnitude of the air springs inner volume. This paper deals with determination of air springs volume using indirect method, which is based on the air pressure measurement and also the comparison of obtained results with the results computed from air springs manufacturer data.
\end{abstract}

Key words: Air Tank Volume Determination, Indirect Method, Air Pressure Measurement

\section{INTRODUCTION}

At our department, we deal for a long time with tuning and continuous tuning of torsional oscillating mechanical systems (TOMS) during their operation in terms of torsional oscillation size (Homišin, 2002, 2014; Homišin and Kaššay, 2014; Grega, 2014). For the TOMS with continuous tuning during their operation we use pneumatic flexible shaft couplings (pneumatic torsional oscillation tuners, thereinafter „pneumatic tuners") developed in our department. Torsional stiffness of the pneumatic tuners can be changed by air pressure adjusting in their pneumatic elements.

Resonances from individual harmonic components of excitation (Fig. 1) can be ejected from operational speed range (OSR) of the mechanical system by suitable value of torsional stiffness $k\left(k_{2}<k_{1}<k_{3}\right)$ and herewith the value of dynamic component MD of transmitted load torque can be reduced (Dresig and Holzweißig, 2007; Baworski et al., 2015; Czech et al. 2014; Czech, 2014; Hal'ko and Pavlenko, 2012; Handrik et al., 2014 Łazarz et al., 2009; Sapietová and Dekýšs, 2016; Wojnar, 2010).

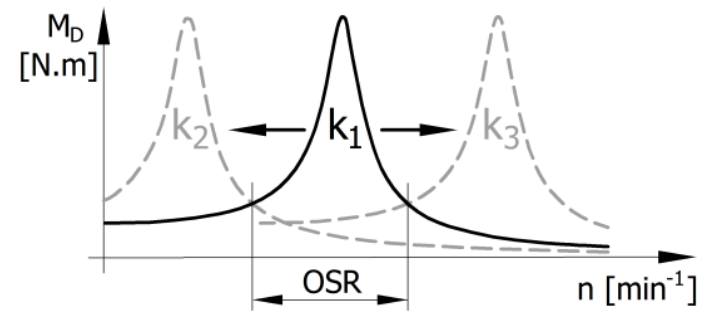

Fig. 1. Mechanical system tuning principle

One of the continuous tuning methods is the application of extremal control - experimental optimization, which main advantage is that we do not need to know a mathematical model of the mechanical system. The extremal control gives us the possibility to minimize the value of dangerous torsional vibration in the TOMS during their operation by adapting the dynamic properties of the system to actual operating parameters and failures (Homišin, 2002, 2014; Homišin and Kaššay, 2014).

Therefore, the new mobile mechanical system (Fig. 2) was built for research and presentation of the TOMS with continuous tuning using extremal control method. The new mobile device is equipped with a special compressed air distribution system, which important components are air springs. Air springs have wide range of use (Kohl and Pešík, 2016; Pešík and Němeček, 1997; Sturm and Pešík, 2017). In this case, the air springs are modified and used as air pressure tanks with various functions in the mobile device. Therefore, it is important to know the magnitude of the air springs inner volume. This paper deals with determination of air springs volume using indirect method, which is based on the air pressure measurement and also the comparison of obtained results with the results computed from air springs manufacturer data.

\section{DESCRIPTION OF THE NEWLY BUILT MOBILE MECHANICAL SYSTEM}

In Fig. 2 we can see that the basic part of this newly built mobile device is a torsional oscillating mechanical system (TOMS). This TOMS consists of 3-phase asynchronous electromotor MEZ 4AP132M-4 (nominal power $7.5 \mathrm{~kW}$ at $1450 \mathrm{~min}^{-1}$ ) (1), whose rotation speed is continuously vector-controlled by the frequency converter Sinamics G120C (2). Electromotor drives the 3-cylinder piston compressor ORLIK 3JSK-75 (3) through the pneumatic tuner of type 4-2/70-T-C (4). The compressor has no flywheel; 
hence it has a higher dynamic impact. The mentioned TOMS is situated on a rigid frame, which is flexibly mounted on a mobile platform (5). The next component situated on the mobile platform is the electronic extremal control system called ESLER (6) and its accessories (e.g. sensors, actuators, etc.). Current level of the ESLER function is in detail described in Homišin and Urbanský, (2015).

The main part of the mobile platform (5) is the special compressed air distribution system (in detail described in Urbanský and Kaššay, 2015), which important components are four air springs of type Rubena 340/3 (Fig. 3). These modified air springs, used as air pressure tanks, have the following functions:

- a compressed air storage for the pneumatic tuner inflation 3 interconnected air springs,

- compressor delivery pipe volume compensation for properly adjustment of compressor delivery pressure and thereby also TOMS load - 1 air spring.

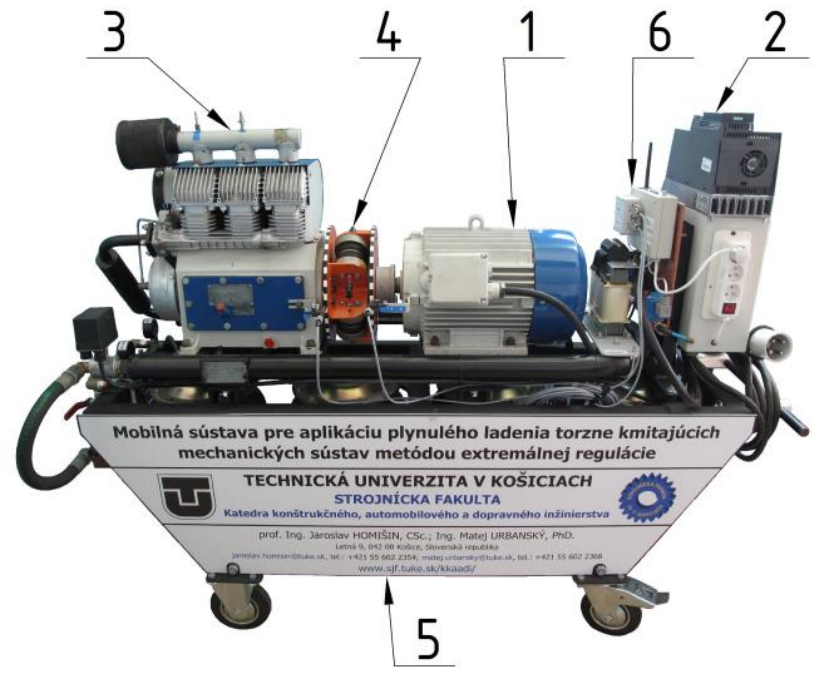

Fig. 2. The newly built mobile device for extremal control presentation: 1 - electromotor MEZ 4AP132M-4, 2 - frequency converter Sinamics G120C, 3 - piston compressor ORLIK 3JSK-75, 4 - pneumatic tuner 4-2/70-T-C, 5 - mobile platform, 6 - electronic extremal control system

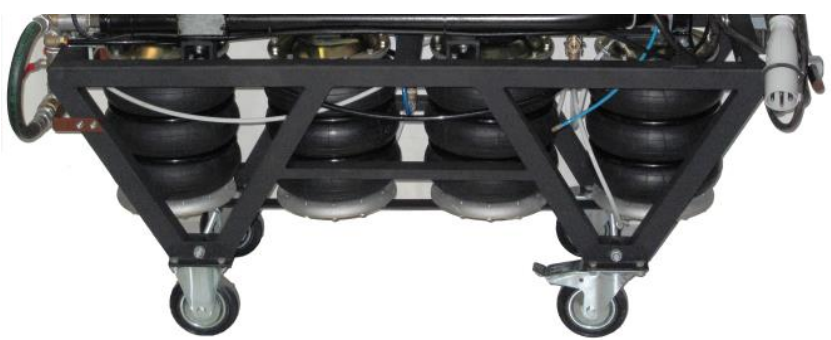

Fig. 3. The mobile platform with 4 air springs Rubena $340 / 3$

\section{COMPUTATION OF THE AIR SPRINGS VOLUME FROM MANUFACTURER DATA}

The following data were available for air springs volume computation (Rubena, 2016):

- air spring volume $V_{H s t a t}$ at static height $H_{\text {stat }}$ (installation height); $V_{\text {Hstat }}=14900 \mathrm{~cm}^{3}=0.0149 \mathrm{~m}^{3}$;

- theoretic force-stroke dependencies at constant air pressures in the air spring.
For our purposes, in Fig. 4 we can see that the stroke $S$ equals to zero at minimal operating height $H_{\min }$; and $S=200 \mathrm{~mm}$ at maximal operating height $H_{\max }$.

In Fig. 5 we can see the dependence of the effective area of the air spring $A_{\text {ef }}$ on the air spring stroke $S$, obtained from above mentioned theoretic force-stroke dependence at constant air pressure in the air spring. This dependence can be described with the following polynomial:

$$
A_{e f}=-0.6438 \cdot S^{2}-0.0564 \cdot S+0.0726 \text {. }
$$

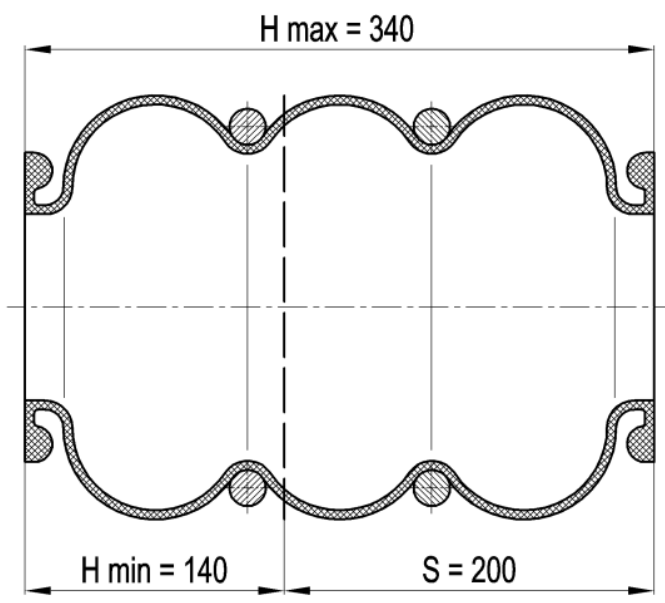

Fig. 4. The air spring stroke

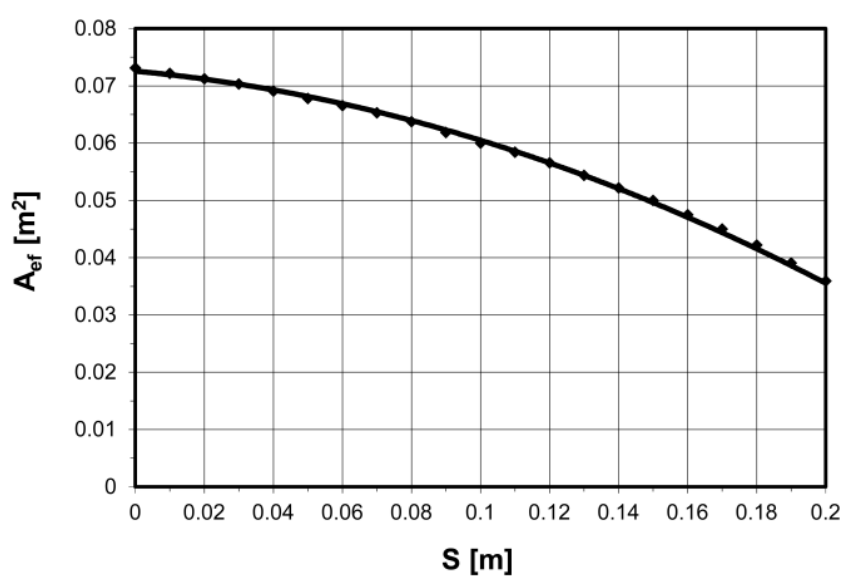

Fig. 5. The dependence of the effective area of the air spring $A_{\text {ef }}$ on the air spring stroke $S$

The axial force $F$ of air spring at its certain stroke can be computed as follows:

$F=p_{p} \cdot A_{e f}[\mathrm{~N}]$

where $p_{p}[\mathrm{~Pa}]$ is an air overpressure in the air spring. Axial stroke of the air spring $d S$ causes an air spring inner volume change $d V$.

The relation between the mechanical work of axial force and the work of compressed air inside the air spring is defined as follows:

$F d S=p_{p} d V$

Using a substitution of equation (2) in equation (3) and additional modification of equation (3) we obtain following equation (4): 


$$
A_{e f} d S=d V \Rightarrow V=\int_{0}^{S} A_{e f} d S
$$

Using a substitution of equation (1) in equation (4) we obtain the following equation (5) for the air spring volume computation:

$$
V=-\frac{1}{3} \cdot 0.6438 \cdot S^{3}-\frac{1}{2} \cdot 0.0564 \cdot S^{2}+0.0726 \cdot S+C
$$

where an integration constant $C=0.00814$ is computed so that air spring volume $V_{\text {Hstat }}=0.0149 \mathrm{~m}^{3}$ is at static height $H_{\text {stat }}$.

\section{DETERMINATION OF THE AIR SPRINGS VOLUME USING INDIRECT METHOD}

In our case, all air springs are installed to maximal installation height $H_{\max }$ (Fig. 4). From equation (5) we can compute that in our case, the 1 air spring volume value is $V_{H \max }=0.01986 \mathrm{~m}^{3}$.

In praxis we observe that with increasing air pressure in air spring at constant stroke, the rubber-textile coat of the air spring stretches up to a certain point. It results in the air spring volume which increases with increasing air pressure in the air spring.

We also have used an indirect method for the determination of air springs volume. This method is based on the air pressure equalization between known and unknown volume, whereby isothermal process was considered (Klenovčanová, 2007).

As the known volume was chosen air pressure tank (1) with inner volume of $0.3 \mathrm{~m}^{3}$ (300 I) (Fig. 6).

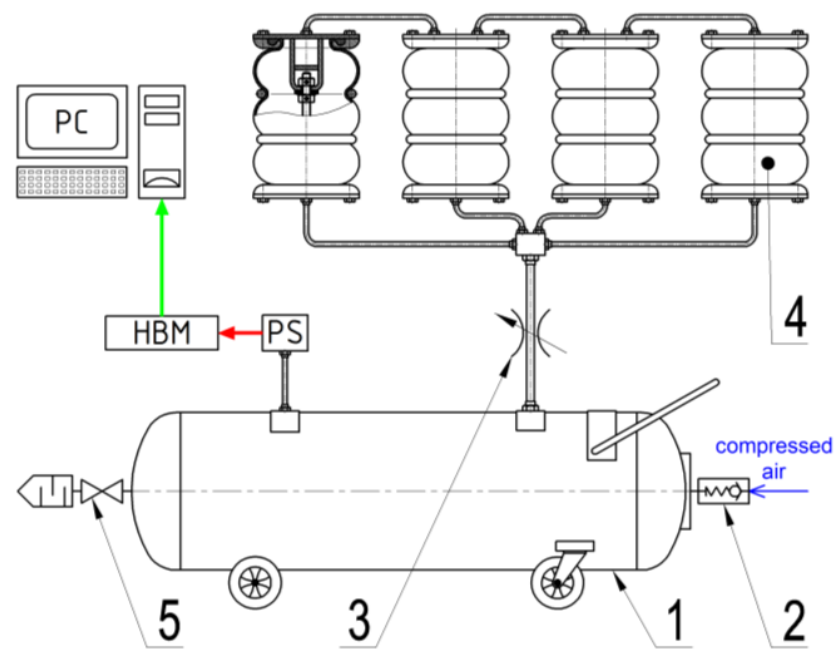

Fig. 6. Devices used for measurement: 1 - pressure tank, 2 - backflow valve, 3 - throttle valve, 4 - air spring, 5 - ball lock valve

Compressed air streams into the pressure tank through backflow valve (2) and it can be deflated using a ball lock valve (5). Four air springs (4) are interconnected and connected with the pressure tank through delivery piping with throttle valve (3). Pressure sensor (PS) (type Meret TSZ, measuring range 0 to $1 \mathrm{MPa}$, combined fault - linearity, hysteresis and reproducibility $=0.1 \%$ of measuring range, in our case $1 \mathrm{kPa}$ ) (Meret, 2017) senses air pressure value in the pressure tank and the measuring equipment HBM Quantum X sends a data to PC.

The measurement principle scheme is shown in Fig. 7. From the figure results the following equations:

$$
\begin{aligned}
& V=V_{1}+V_{2} ; V=V_{1}^{\prime}+V_{2}^{\prime} ; V_{1}+V_{2}=V_{1}^{\prime}+V_{2}^{\prime} \\
& p_{1} \cdot V_{1}=p \cdot V_{1}^{\prime} ; p_{2} \cdot V_{2}=p \cdot V_{2}^{\prime} ; V_{1}+V_{2}=\frac{p_{1}}{p} \cdot V_{1}+\frac{p_{2}}{p} \cdot V_{2}
\end{aligned}
$$

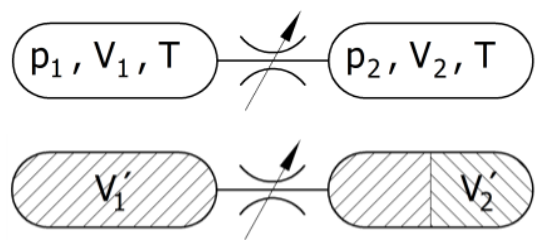

$\mathrm{p}, \mathrm{V}, \mathrm{T}$

Fig. 7. Scheme of measurement principle tions:

By modification of equation (7) we obtain the following equa-

$V_{1} \cdot\left(1-\frac{p_{1}}{p}\right)=V_{2} \cdot\left(\frac{p_{2}}{p}-1\right) ; V_{1} \cdot\left(\frac{p-p_{1}}{p}\right)=V_{2} \cdot\left(\frac{p_{2}-p}{p}\right)$

$V_{2}=V_{1} \cdot\left(\frac{p-p_{1}}{p_{2}-p}\right)$

$V_{2}=V_{1} \cdot\left(\frac{p_{p}+p_{a}-p_{p 1}-p_{a}}{p_{a}-p_{p}+p_{a}}\right)$

where $p_{p}[\mathrm{~Pa}]$ is an air overpressure after air pressure equalization, $p_{p 1}[\mathrm{~Pa}]$ is an air overpressure in the pressure tank, $p_{a}[\mathrm{~Pa}]$ is atmospheric pressure $(101325 \mathrm{~Pa}), V_{1}$ is inner volume of the air pressure tank $\left(0.3 \mathrm{~m}^{3}\right), V_{2}$ is inner volume of the four interconnected air springs and piping. By modification of equation (10) we obtain the following equation:

$V_{2}=V_{1} \cdot\left(\frac{p_{p 1}-p_{p}}{p_{p}}\right)$

In order to maximize measurement accuracy, it is advisable to observe the following rules:

- the whole measurement device should be pressure-tight as good as possible (i.a. Scully, 2015),

- considering the isothermal process, it is important to wait long enough for $p_{p}$ and $p_{p 1}$ values consolidation (Abbas et al., 2011; Massey, 2006),

- it is necessary to use very accurate pressure sensor,

- it is necessary to know the accurate value of known volume.

In Fig. 8 we can see the results of realized measurements. It was executed 9 measurements at $p_{p 1}=400,450,500,550,600$, $650,700,750$ and $800 \mathrm{kPa}$. The volume of 1 air spring $V_{H \text { max }}$ at maximal installation height $H_{\max }$ is computed without the piping volume. In the figure we can see that the value of $V_{H \max }$ increases degressively with increasing $p_{p}$ values according to equation:

$V_{H \max }=-8.463 \cdot 10^{-6} \cdot p_{p}^{2}+1.207 \cdot 10^{-2} \cdot p_{p}+15.256$.

This fact is probably caused by extensibility of the air springs rubber-textile coat in radial direction, because the air spring is rigid in axial direction. 


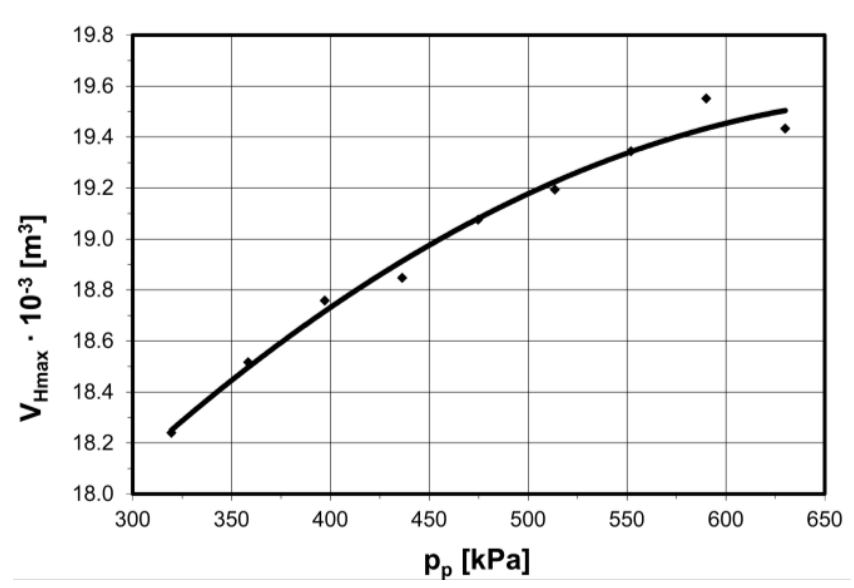

Fig. 8. One air spring volume value $V_{H \max }$ dependent on air overpressure $p_{p}$ in the air spring.

\section{CONCLUSIONS}

Comparing the air spring volume values we can see that values of $V_{H \max }$ shown in Fig. 8 approximate at higher $p_{p}$ values to the reference value $V_{H \max }=0.01986 \mathrm{~m}^{3}$ computed from equation (5). All by us measured values of $V_{H \max }$ are smaller than the reference value. This is probably caused by the facts that inside of our air springs are in addition excessive stroke prohibitive components.

The accuracy of measured results is difficult to evaluate, because we have not accurate results measured by another method and the volume of air springs is not constant, as we can see at air springs inflation. Therefore, it is advisable to verify the accuracy of given method by measuring of both known volumes.

In order to maximize measurement accuracy, it is advisable to observe the rules mentioned in previous chapter 4 . We could say that these rules are simultaneously disadvantages of the given measurement method. Advantage of the method is that we could determine approximate (inner) volume of intricate shaped objects.

\section{REFERENCES}

1. Abbas R., Ihmels C., Enders S., Gmehling J. (2011), JouleThomson coefficients and Joule-Thomson inversion curves for pure compounds and binary systems predicted with the group contribution equation of state VTPR, Fluid phase equilibria, 306, 181-189.

2. Baworski A., Garbala K., Czech P., Witaszek K. (2015), Estimation of the ability to use a mass of air from a moving vehicle in wind turbine propulsion, Scientific Journal of Silesian University of Technology, Series Transport, 88, 5-17.

3. Czech P. (2014), Conception of use vibroacoustic signals and neural networks for diagnosing of chosen elements of internal combustion engines in car vehicles, Scientific Journal of Silesian University of Technology, Series Transport, 82, 51-58 (in Polish).

4. Czech P., Wojnar G., Burdzik R., Konieczny Ł., Warczek J. (2014), Application of the discrete wavelet transform and probabilistic neural networks in IC engine fault diagnostics, Journal of Vibroengineering, 16, 1619-1639.

5. Dresig H., Holzweißig F. (2007), Dynamics of Machines, Springer, Berlin Heidelberg (in German).
6. Grega R. (2014), Examination of applicated pneumatic flexible coupling and its effect on magnitude of vibrations in drive of belt conveyer, Scientific Journal of Silesian University of Technology. Series Transport, 85, 21-25.

7. Hal'ko J., Pavlenko S. (2012), Analytical suggestion of stress analysis on fatigue in contact of the cycloidal - vascular gearing system, Scientific Journal of Silesian University of Technology. Series Transport, 76, 63-66.

8. Handrik M., Vaško M., Kopas P., Sága M. (2014), Effective finite element solution and post-processing for wide load spectrum, Communications, 16(3A), 19-26.

9. Homišin J. (2002), New types of pneumatic flexible shaft couplings: development, research, application, Vienala, Košice (in Slovak).

10. Homišin J. (2014), New methods for tuning of mechanical systems during operation in steady state, Scientific Journal of Silesian University of Technology. Series Transport, 85, 49-55.

11. Homišin J., Kaššay P. (2014), Experimental verification of the possibility using pneumatic flexible shaft couplings for the extremal control of torsional oscillating mechanical system, Diagnostyka, 15(2), 7-12.

12. Homišin J., Urbanský M. (2015), Partial results of extremal control of mobile mechanical system, Diagnostyka, 16(1), 35-39.

13. Klenovčanová A. (2007), Thermomechanics, Faculty of mechanical engineering, Technical University of Košice (in Slovak).

14. Kohl O, Pešík L. (2016), Evaluation of a driver's seat's dynamic properties, Scientific Journal of Silesian University of Technology. Series Transport, 91, 59-69.

15. Lazarz B., Wojnar G., Madej H., Czech P. (2009), Evaluation of gear power losses from experimental test data and analytical methods, Mechanika, 80(6), 56-63.

16. Massey, B. (2006), Mechanics of fluids, Taylor and Francis, London.

17. Meret (2017), Pressure transmitters type TSZ with a sensor with metal diaphragm. Accessed: 13.04.2016. Available at: http://www.meret.sk/en/produkty/meranie-tlaku/snimacetlaku/snimace-tlaku-typu-tsz/

18. Pešík L., Němeček P. (1997), Monitoring of vibration of machines with an elastic support, Insight, 39, 566-568.

19. Rubena (2016), Rubber-textil products, air springs. Accessed: 31.03.2016. Available at: http://www.rubena.cz/air-springs/t-659/.

20. Sapietová A., Dekýš V. (2016) Dynamic analysis of rotating machines in MSC.ADAMS, Procedia Engineering, 136, 143-149.

21. Scully, L. (2015), Make pneumatic connections air tight. Accessed: 13.04.2016. Available at: http://www.hydraulicspneumatics.com/fitting s-couplings/make-pneumatic-connections-air-tight/

22. Sturm M., Pešík L. (2017), Experimental determination and simulation of spring-tensions under working conditions of a vibrating bowl feeder, Acta Mechanica et Automatica, 11, 243-246.

23. Urbanský M., Kaššay, P. (2015), The new realized mobile device for extremal control research and presentation, Scientific Journal of Silesian University of Technology. Series Transport, 89, 173-178.

24. Wojnar G. (2010), Using of torsional vibrations velocity for the detection of toothed wheels' fault, Scientific Journal of Silesian University of Technology. Series Transport, 66, 123-128.

This paper was written in the framework of grant projects: VEGA 1/0473/17 "Research and development of technology for homogeneous charge self-ignition using compression in order to increase engine efficiency and to reduce vehicle emissions", KEGA 041TUKE-4/2017 "Implementation of new technologies specified for solution of questions concerning emissions of vehicles and transformation of them into the educational process in order to improve quality of education" and PhD. Student's and Young Researcher 's Project: "Solution of a control system element for mechanical systems continuous tuning". 